\title{
Bioprosthetic mitral valve effective orifice area by phase-contrast CMR. An in vitro comparison with Doppler echocardiography
}

Dimitrios Maragiannis, Matthew Jackson, Karen Chin, Kyle Autry, Stephen Igo, Dipan J Shah, Stephen H Little

From 17th Annual SCMR Scientific Sessions

New Orleans, LA, USA. 16-19 January 2014

\section{Background}

Introduction: Current guidelines for the functional evaluation of bioprosthetic heart valves recommend the effective orifice area (EOA) as the product of the transvalvular stroke volume divided by Doppler derived diastolic time velocity integral (TVI). Phase contrast CMR may offer an alternative imaging modality to assess bioprosthetic valve EOA when Doppler methods are technically limited or unreliable.

\section{Methods}

Our circulatory loop includes a mock ventricle and a heart valve imaging chamber that has been fabricated using MRI-compatible components. In this study 3 different sized stented porcine mitral valve bioprostheses were evaluated $(27 \mathrm{~mm}, 29 \mathrm{~mm}, 31 \mathrm{~mm})$ replicating three different hemodynamic conditions with forward stroke volume of $70 \mathrm{ml}, 90 \mathrm{ml}$ and $110 \mathrm{ml}$ respectively at a beat rate of $70 \mathrm{bpm}$. Imaging was performed with a

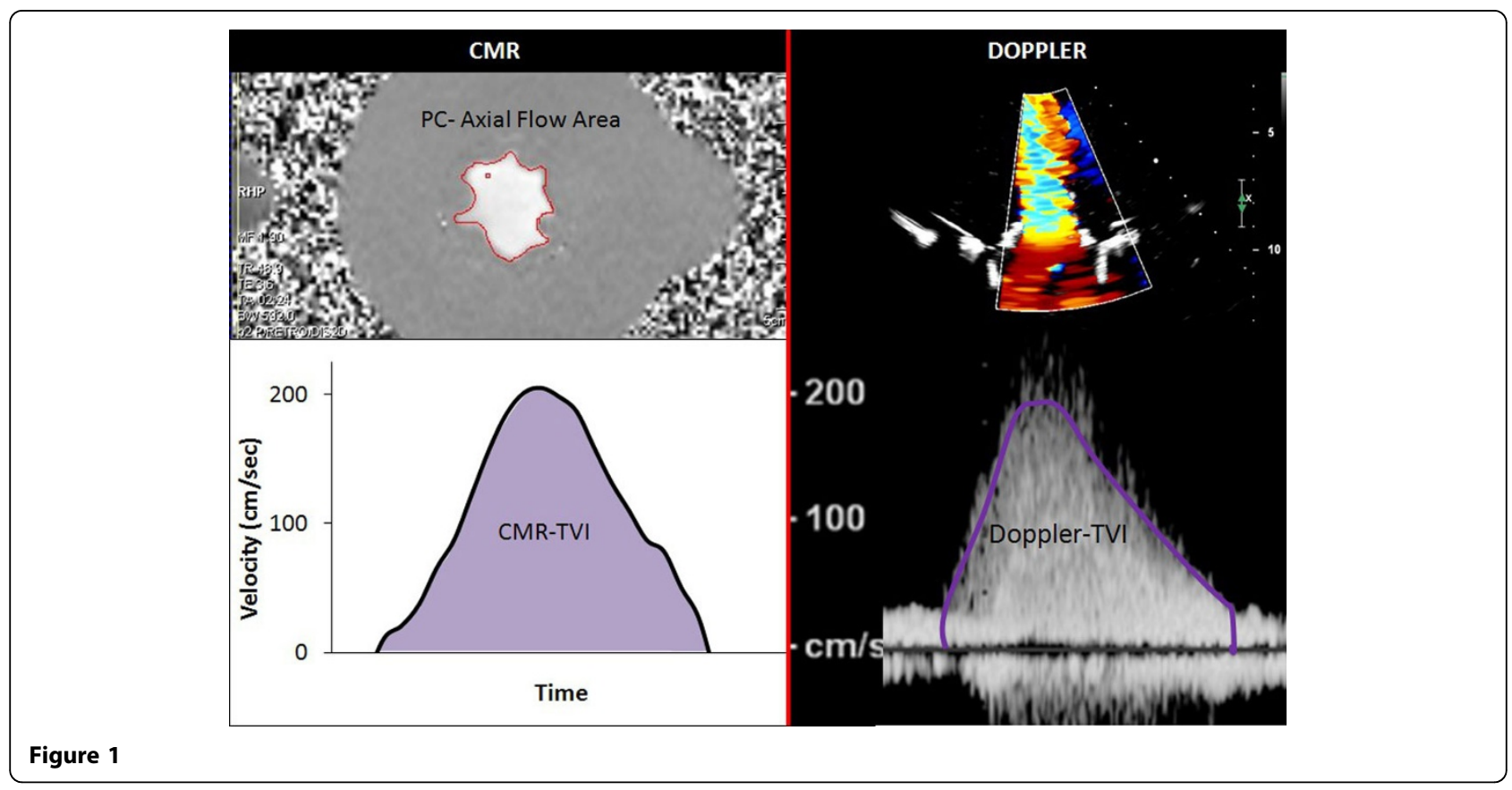

Cardiac MRI, Houston Methodist Hospital, Houston, Texas, USA

(c) 2014 Maragiannis et al.; licensee BioMed Central Ltd. This is an Open Access article distributed under the terms of the Creative 
1.5T Siemens Avanto scanner. CMR imaging parameters consisted of 25 phases, slice thickness $4 \mathrm{~mm}$, spatial resolution of $138 \times 256$ and temporal resolution of $49 \mathrm{msec}$. Phase contrast pulse sequences were acquired and peak instantaneous velocities were plotted throughout the diastolic filling period. Stroke volume was measured by MRI-compatible high fidelity flow transducer. The velocity time integral of peak velocity was calculated by tracing the area under the curve and CMREOA $(\mathrm{cm} 2)$ was calculated by dividing the forward flow (cm3) by the MRI-derived TVI $(\mathrm{cm})$. Doppler derived EOA was determined by dividing the stroke volume by the continuous wave Doppler TVI.

\section{Results}

Bioprosthetic mitral valve diastolic flow area was assessed for 3 different sized valves each at 3 flow volume conditions $(\mathrm{N}=9)$. Doppler-EOA and CMREOA were measured and compared for each condition. CMR-derived TVI demonstrated a strong and statistically significant correlation with Doppler-derived TVI $(\mathrm{r}=0.97, \mathrm{p}<0.001)$. CMR-EOA also revealed a strong and statistically significant correlation with Doppler derived EOA $(\mathrm{r}=0.90, \mathrm{p}=0.001)$. Mean EOA difference was $0.2 \mathrm{~cm} 2 \pm 0.13$. The lower temporal resolution of phase contrast CMR velocity determination may have led to the lower TVI values and slightly larger EOA calculation compared to Doppler TVI method

\section{Conclusions}

In this study we report a novel method to determine mitral prosthetic valve effective orifice area using phase contrast CMR values. We demonstrate a strong correlation with the current Doppler standard method to derive EOA. CMR-derived EOA may be an important parameter of prosthetic valve function when Doppler methods are unobtainable or unreliable.

\section{Funding}

AHA beginning grant in aid.
doi:10.1186/1532-429X-16-S1-T3

Cite this article as: Maragiannis et al:: Bioprosthetic mitral valve effective orifice area by phase-contrast CMR. An in vitro comparison with Doppler echocardiography. Journal of Cardiovascular Magnetic Resonance 2014 16(Suppl 1):T3.

\section{Submit your next manuscript to BioMed Central} and take full advantage of:

- Convenient online submission

- Thorough peer review

- No space constraints or color figure charges

- Immediate publication on acceptance

- Inclusion in PubMed, CAS, Scopus and Google Scholar

- Research which is freely available for redistribution

Submit your manuscript at www.biomedcentral.com/submit 